\title{
A first person view on absolute musical pitch
}

\author{
Krasimira Georgieva Fileva-Ruseva \\ Faculty of Music Pedagogy, Academy of Music, Dance and Fine Arts - Plovdiv, Bulgaria, Europe \\ Email address: \\ krassyfilleva@abv.bg
}

\section{To cite this article:}

Krasimira Georgieva Fileva-Ruseva. A First Person View on Absolute Musical Pitch. International Journal of Literature and Arts. Special Issue: Musical Theory, Psychology and Pedagogy. Vol. 2, No. 5-1, 2014, pp. 8-13. doi: 10.11648/j.ijla.s.2014020501.12

\begin{abstract}
Absolute musical pitch is an inborn talent which allows the people, endowed with it to identify the exact pitch of a specific tone without using a predefined reference point, regardless of the timbre of the source of the sound and of whether they are hearing a single tone, a logically organized melodic sequence, a succession of tones not following a definite logic, harmonic intervals or assonances. This type of pitch cannot be achieved through pedagogical influence. The people, gifted with absolute pitch, can hear the names of the tones simultaneously with the very sounding of the tones. Among the advantages of absolute pitch are the following: The fast and accurate identification of the tone names is useful to composers who, in their artistic project, have posed onomatopoeic tasks. Due to the fact that a person with absolute pitch does not need to use as a reference point the identification of modal functions to be able to recognize the tones of a melody, he/she is in a "more favorable" position, compared to the one, who has gained relative pitch, through working with musical pieces, in which there is no tonal organization. This is extremely valuable for performers and conductors. The speed, accuracy and confidence in hearing the tone names by the people with absolute pitch allows for some unexpected intonation movements to be exactly and easily identified right at the moment they are being heard. This is very useful, for instance, when collecting and writing down folk songs. The people with absolute pitch are faced with some problems, as well, like: The tolerance, related to absolute pitch (the ability, which allows, for example, to recognize a range of frequencies around 440 Hertz as "a"), and the absence of need for education, which would include the intonationally correct memorization of interval-templates to use later as reference points, are reasons that could explain the inaccurate pitch intonation in singing often seen in musicians with absolute pitch. The tolerance, related to absolute pitch, could become the reason for it to be lost. The ones, who possess absolute pitch, hear tone names, together with sounds that have not been produced by a musical instrument or a voice, but by other sound sources. The tone names coming from every direction - letters or syllables (depending on whether the musician is more used to the letter or the syllable names of tones), from which different words can be formed or which can lead the perceiver to associations in an unexpected direction, distract the mind.
\end{abstract}

Keywords: Music, Musical Abilities, Absolute Musical Pitch

\section{Introduction}

The discovery of a certain talent at an early age often leads to the focusing of personal development into a specific direction, even before the child is able to express their desires and interests. The natural talent that played this role in my life was my absolute pitch.

\section{Regarding the Specific Features of Absolute Pitch}

This is an inherent talent that enables a person to identify the exact frequency of a given tone without the help of a predefined reference point (people, who have developed the more commonly found pitch - relative pitch - usually use as a reference point the tone "a" from the first octave. Sometimes it is necessary to supplement this reference point with the tonic chord of a given tonality. The ability to identify tone pitches in melodies and assonances, when having relative pitch, is achieved with the help of continuous and systematic musical auditory training and not all students are able to achieve excellent results). The ones gifted with absolute pitch can always identify the tone pitch, regardless of the timbre of the sound's source (the tone does not even have to be produced by a musical instrument or human voice - if the sound heard has a relatively constant frequency, i.e. a tone, it is recognizable) and it is not important whether a 
single tone is heard, a logically organized melodic sequence, a sequence of tones, not obeying a specific logic, harmonic intervals or assonances. This type of pitch hearing cannot be achieved through pedagogical influence.

The prerequisites for the existence of absolute pitch have not yet been determined. Neither has it been made clear whether this much more rarely found way of understanding tone pitches is the result of an anatomical function or a psychical quality. Psychologists, who have shown interest in this property of auditory sense, limit their interest mainly to the question of whether this quality is hereditary in any way and how it is passed on, if it is inherent. Up until now, the inheritance has not been proven. There are known cases of absolute pitch found in children, whose parents have been professional musicians, but the number of people gifted with absolute pitch, who have no relatives in the musical profession, is not smaller. My mother, who works professionally in music, does not possess absolute pitch. The environment in which I grew cannot explain the existence of absolute pitch among my characteristics, because my daughter, raised in the same conditions (even with yet another professional musician in the family, i.e. myself) is not gifted with absolute pitch and has not chosen a career path in music.

Absolute pitch was manifested at an early stage, in my case. At the age of one year and twenty days, I re-created correctly a basic melody. My first performances were accurate when re-creating a gradual (sequent) descending movement, but faltering in ascending movements. After only a few days, I was already able to sing the song properly. This was witnessed by my mother - a musical theory specialist and pedagogue, Professor in the Academy of Music, Dance and Fine Arts - Plovdiv. Soon after that, I was able to sing (but not pronounce in a discernable way the lyrics) the Bulgarian folk song "Petruno, Mome Hubava" (Figure 1), which I had memorized without intent.

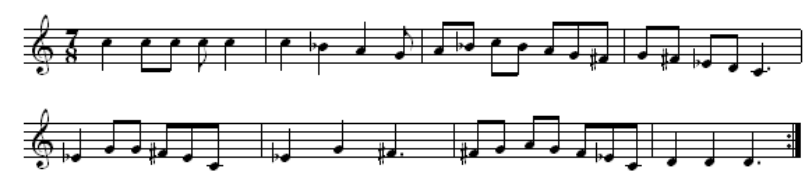

Figure 1. "Petruno, Mome Hubava”, Bulgarian folk song

The fact that I was able, repeatedly, to sing this complex in intonational aspect song, especially the major seventh $\mathrm{d}^{1}-$ $\mathrm{c}^{2}$, which appears between the last tone and the next starting tone in the repetition of the melody for the second verse, as well as that I was able to re-create the song always from the same initial tone (actually, I have never, even to this day, been able to imagine that this song could be sung from a lower or a higher tone), was already a certain indication that maybe I possessed absolute pitch. A neighbor commented on my "vocal performances": "This kid cannot speak, but knows how to sing!“"

The early manifestation of absolute pitch, at an age, in which a child is not being taught yet, shows that this is an inherent characteristic of hearing.
The suggestion that absolute pitch is not an anatomical quality is also supported by the following case of impairment of the auditory-vestibular apparatus - unilateral labyrinthopathy. Tests show that the curve of bone conduction repeats the curve of audibility, which means that, apart from the internal ear, the cochlear (auditory) nerve is also affected. Despite this serious impairment, absolute pitch remains intact.

Regarding the specifics of hearing with absolute pitch, I would like to again refer to my autobiographical data. I was four and half years old, when my mother decided to teach me the musical notes. Showing to me the notes "c $c$ " and " $\mathrm{d}^{1 \text { " }}$ with the corresponding keys on the piano keyboard and their places on the staff, my mother asked me "Which one is lower, c or d?", I not only answered correctly, but also asked "Which are the notes above them?" When she taught me the tone names of the notes, their place on the staff and on the keyboard, it became clear that I could sing and identify their sound accurately. On the question "How do you recognize them?" I answered: "They sing their names themselves!". All of my colleague musicians, who possess absolute pitch, also say that they hear the tone names at the same time of hearing the tones.

\section{About the Need to Combine Absolute Pitch with Other Qualities}

It is a known fact that one of the great composers of the past, who had absolute pitch, was Robert Schumann. Due to a disease of the hands he was not able to become a successful piano performer, but he left the world incredible works for piano, chamber music and symphonies, together with interesting literature works. Apparently, he possessed a fortunate combination of musical and linguistic intelligence (terms by H. Gardner). An opposite case is the one of a student in the Musical School for Secondary Education "Dobrin Petkov" - Plovdiv. It is a very characteristic case of the specific difficulties that every person, gifted with absolute pitch, encounters. In a solfège class, the teacher plays on the piano the tones es ${ }^{1}-b^{1}$ and asks the question "what harmonic interval are you hearing?" The answer of the student is: "I cannot tell - what does d sharp - b mean?" The pedagogue suggest to the student to replace enharmonically one of the two tones, he is hearing, so that the tones have the same chromatic signs, but the student again is not able to do that. There are three possible solutions to this task, depending on the abilities of the student:

- That student played the piano, which means he was familiar with the equal temperament, in which the enharmonically interchangeable tones have the same frequency (sound the same) and the same key is used for each group of enharmonically interchangeable tones. For that reason, the first option is to try to picture whichever one of the two keys on the piano, on which that interval is performed, and to try to remember what other tone can be played on that same key. This method 
can be used by people with well-developed spatial intelligence.

- Another solution - the most often applied - is to remember the groups of enharmonically interchangeable tones and to decide which of the tones in the given interval should be changed, so the two tones would have the same chromatic signs. This solution requires the presence of developed linguistic intelligence.

- The third possible solution (only hypothetical, it is not used) is calculation - for example, there is only a semitone between the tones $\operatorname{dis}^{1}-\mathrm{e}^{1}$, the "distance" between $\mathrm{e}^{1}$ and $\mathrm{b}^{1}$ is three tones (this is the so called "tritone" interval), $1 / 2+3=31 / 2$, which represents the tonal span of a perfect fifth. This method of work requires prevalence of the logical-mathematical intelligence.

Despite the three above-mentioned solutions, the student was not able to deal with the easy for his classmates task. The one gifted with absolute pitch does not need to search for the name of the second tone, after identifying the interval, formed between the two tones, in the way students, who are developing their relative pitch, need to do, i.e. this student hears the exact tonal pitches first and after that has to determine the interval between them. Because of this, the one possessing absolute pitch has to use other methods to solve an elementary task. These methods, however, require a certain level of development of some of the above-mentioned types of intelligence. Most frequently used is the second method described, which in the given situation was also suggested by the teacher. The student did not manage to change enharmonically one of the two tones, in order to make the task easier (and later on in his studies - to write down correctly the music he was hearing) with the correct one of the enharmonically interchangeable tones. The last skill is acquired in the same way as correct spelling is studied. This means that the failure to solve the above mentioned task by a student in a secondary school of music, i.e. one who has already acquired a certain level of experience, with a specific method prescribed, shows a lower level of development of linguistic intelligence.

It is well-known that the great German composer Richard Wagner, who did not possess absolute pitch, was very annoyed by the fact that a certain orchestra player, from the opera orchestra he was conducting, could always point out to the exact instrumentalist in the large orchestral staff who had played an incorrect tone. Wagner used to call this orchestral player "a donkey with a tuning fork in his ears". To be able to identify the incorrectly intonating performer among all the orchestra players would require a combination of absolute pitch and good spatial hearing. The sense of direction of sound is not one of the features characteristic to absolute pitch. The example used suggests that the combination of absolute pitch and spatial hearing is an essential quality, needed by conductors.

Another possible reason for which the presence of absolute pitch would not provide good results in the musical profession could be the insufficient and unbalanced development of the other musical abilities. In this regard, the following case is indicatory - a student in the Musical School of Secondary Education "Dobrin Petkov" - Plovdiv, who possessed absolute pitch, but despite this was helpless in encoding (writing down) in notes the music he was hearing. The problem consisted in the following - the very notes, with which he was writing down the melody, were correct (he was not even using the key signatures of tonality, but was writing the signs for raising or lowering the pitch in front of each note), however, the student left no indication of the note value. This shows an absence of methro-rhythmic sense - i.e. the student is not capable of perceiving the temporal organization of the sound flow. Even though the student managed to graduate also from a School of Higher Education in Musical Pedagogy at the end, he did not have a career as a musician, i.e. without the appropriate development of the methro-rhytmic sense, absolute pitch remained unusable.

\section{Absolute and Relative Pitch}

In my childhood years, soon after it was proven with certitude that I had absolute pitch, my teacher in solfège decided to test me, playing the tone $\mathrm{f}^{1}$ and asking me which tone I was hearing. I answered: "Between e and f". The teacher was surprised at first, then he remembered that the piano had not been tuned recently and was a bit "low". The reason for my peculiar answer was that the piano, on which I had perceived and memorized initially the tone frequency, was better tuned, respectively - sounded a little bit "higher". In the beginning of their musical studies, the ones gifted with absolute pitch listen for the first time to the tones with their names and memorize exactly those tone pitches, which they have perceived on the given musical instrument (usually some of the earliest classes in solfège are done with the help of a piano; but tones on the different pianos have some, even if minimal, differences in their pitches). Those exact pitches on that specific piano, on which they were perceived, will be the templates for tone names for some time. Afterwards, with more extensive activities with music and on different pianos, and if possible - on other musical instruments, and through singing, the possessor of absolute pitch develops a "tolerance", for example the tones in the range of what frequencies around 440 hertz can be considered to be "a".

To clarify some of the characteristics of the perception of music being heard by people with absolute pitch, I would like to compare the way of acquiring the needed information when hearing an elementary melodic interval (Figure 2) between them and the people who have developed relative pitch.

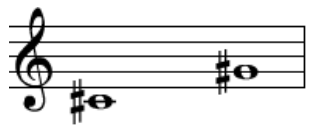

Figure 2. A perfect fifth as an example of the hearing in musicians gifted with absolute piths and those who have developed relative pitch 
At the initial stage of their education in music, a person gifted with absolute pitch hears for example $\operatorname{cis}^{1}-$ as ${ }^{1}$. Similar "mistakes" in perception are so commonly observed that they can be used as one of the methods of determining the existence of absolute pitch. If the student possesses also the needed intellectual qualities, they soon learn the rule that the signs for alteration in a given interval have to be the same Then the way to calculate will be, for example, the following "The tones I am hearing are $\operatorname{cis}^{1}-\mathrm{as}^{1}$, but since it is not correct to specify the melodic interval with different chromatic signs for the tones, I have to replace enharmonically one of the tones. Between the tones des ${ }^{1}$ and as $^{1}$ (or cis ${ }^{1}$ and gis $^{1}$ ), there are 5 degrees of the scale, the interval perfect fifth consists of five degrees, i.e. the interval between the tones is a perfect fifth". This indicates that in order for the absolute pitch to be usable, it is required for it to be combined with a certain level of linguistic intelligence. In the course of musical training, the one gifted with absolute pitch, learns the skill to listen to the melodic intervals with identical chromatic signs. This shows that the talent absolute pitch is subject to further development. Nevertheless, the skill to hear correctly all of the enharmonic intervals is never fully perfected. What helps in this case is the knowledge of the rules of notation "spelling".

The people, training their relative pitch, at first learn to identify correctly the direction of the melodic movement. Afterwards, they develop a musical auditory notion template, for each musical interval (later on - also for the harmonic ones). This is achieved with the help of short melodies, in which a given interval stands out as characteristic (sounds more prominently). In exercises, separate melodies are used - for each ascending interval, as well as for each of the descending ones; additionally, for the intervals second, third, sixth and seventh, the pedagogue has to provide examples for each of their two variants - major and minor interval. For example, the following Bulgarian folk song would be suitable for the creation of a template for the ascending major second:

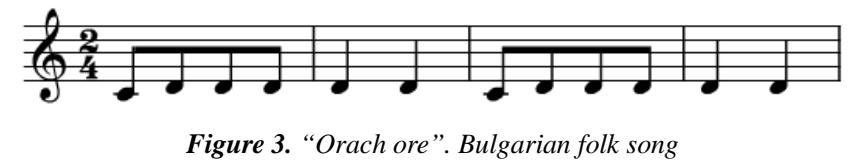

To compare and long-term memorize the difference in sounding between the minor and major second, it would be appropriate to use another Bulgarian folk song:

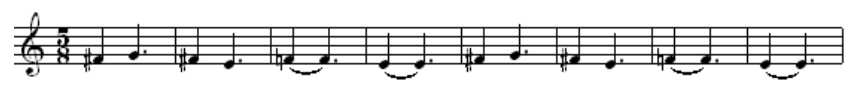

Figure 4. "Peperuda lyatna, lyatna i prolyatna". Bulgarian folk song

In order to increase the efficiency of relative pitch, another group of methods is used, related to the realization, consolidation in the mind and confident identification of the modal functions of each note in the specific tonality.

In Figure 2 (the melodic interval $\operatorname{cis}^{1}$ - gis ${ }^{1}$ ) the student, who has developed relative pitch, first has to identify the interval between the given (necessary for them) reference point $\mathrm{a}^{1}$ and the first tone of the melodic interval in the example $\left(\operatorname{cis}^{1}\right)$. The student does this with the help of the relevant, developed in previous classes, template interval. In this case, the student points out that the interval is a minor sixth. At such a "distance" from $\mathrm{a}^{1}$ is cis ${ }^{1}$, therefore cis ${ }^{1}$ is the first tone of the melodic move, given in the example. The next melodic interval (also established with the help of a template) is the ascending major fifth, which means that the second tone is gis ${ }^{1}$. Even though the reasoning of the ones, who have acquired relative pitch, is mediated (they need an initial reference point, as well as to test against sound templates), it turns out that it is more intuitive - the people with developed relative pitch rely more on pre-developed musical auditory notions (they work on the level of selecting an image template). The person, working with relative pitch, does not have to conform with "grammar" rules for the correct writing of chromatic signs, which is required by the gifted with absolute pitch. For the student with relative pitch it is important, however, to achieve a much greater level of development of musical auditory notions. From this comparison of the methods of solving a problem between the people gifted with absolute pitch and the ones, who have developed relative pitch, it becomes clear that for absolute pitch to "work" it is necessary for it to be combined with linguistic intelligence.

\section{The Advantages of the Presence of Absolute Pitch}

- As a successful example of a professional realization of a person, gifted with absolute pitch, I will quote the case of a certain accompanist. He reads effortlessly sheet music a prima vista, regardless of the complexity of the musical texture, in the provisioned tempo, follows accurately the solo player, who he is accompanying, reacting correctly to his changes in tempo, dynamics and agogic deviations. After a few playings, he learns the score by heart and each time, when the solo player, also playing by heart, forgets his part, skips through a certain text or goes back and performs a specific passage again, the accompanist plays alongside without an error. Even more unique is his ability (which very few accompanists are happy to have) consisting in the following: when he accompanies a singer and the vocalist unintentionally changes the tonality (most often sings lower), the accompanist immediately hears accurately the difference and reacts at the same moment, transposing his score. All of these abilities show for the positive effect of absolute pitch in the work of that accompanist, which makes him an invaluable partner on the concert stage.

- The fast - achieved at practically real time, and accurate identification of the tone names is of great importance to composers, who, in their artistic project, 
have chosen onomatopoeic tasks. The sounds, that the author of music wants to imitate, if they possess absolute pitch, they will hear "by default" with the tone names of the source of the sound itself.

- Since people gifted with absolute pitch do not need to use as a reference the identification of modal functions to recognize the tones in a melody, they are in a more "advantageous" position in comparison to the ones, who have acquired relative pitch, through working with musical pieces, in which a tonal organization is absent. The first ones understand the logic of development and memorize such pieces without greater difficulty than comprehending tonally organized works of art. This peculiarity is "of use" mostly to performers and conductors.

- The speed, accuracy and confidence in hearing the tone names by the ones, gifted with absolute pitch, allows them to identify correctly certain unconventional, strange, unexpected intonation movements, at the same moment they hear them, and effortlessly, at that. This is an extremely valuable quality for example when collecting and writing as sheet music folk songs, because the gifted with absolute pitch hears the melody "in tone names".

- The people, who possess absolute pitch, always remember the music heard in the tonality it has been perceived at the first listening. This quality benefits the accuracy of musical auditory notions. One of the situations, in which this would be helpful, is also when encoding as notation melodies with research purposes.

\section{Problems of Having Absolute Pitch}

- Tolerance, which is developed when having absolute pitch, as well as the absence of the need of the specific training, in which template intervals are memorized intonationally correct to serve as a reference point, these are reasons that might explain the common among musicians with absolute pitch imprecise intonating.

- Despite the tolerance in absolute pitch, there are certain problems with the perception of specific tone pitches that often remain and surprise the people with absolute pitch, when they would least expect similar difficulties. In this relation, I can talk about the following case studying in the first year in the Faculty of Musical Instruments at the State's Music Academy "Professor Pancho Vladigerov" in Sofia (i.e. long after I had developed the above-mentioned tolerance in my hearing), I was preparing Etude op. 10 № 5 of F. Chopin. On the piano I was using in my rented room, the tonality sounded normal as compared to my mental image of Ges dur, but each time, I had to play the Etude on the grand piano at the Academy, on which the classes in piano were held, to my horror, sounding under my fingers was the enharmonic tonality Fis dur and I had to transpose, in order to be able to follow my own performance. This happened every time, when I had classes in piano, i.e. two times a week. Professor Lily Atanasova, with whom I was studying, quickly understood that I had a problem with the enharmonic tonalities Fis and Ges dur, (in fact, I had problems only on the grand piano in her classroom); for that reason, she assigned to me the task to learn a large number of pieces in these tonalities in that academic year.

- Up until the 1990's, music recordings were listened to on gramophone records. A problem existed, however the revolutions (the speed of turning) of the records were not always correct. This reflected on the pitches of the tones, i.e. very often the music on the record was re-created in a tonality different from the original. This difference impeded the people with absolute pitch (especially when we had to follow with sheet music a work of complex multi-plane texture), because we had to transpose the sheet music on the spot, in order to achieve a synchrony between the notation and the sound from the gramophone record.

- The fact that people with absolute pitch hear, together with their tone names, sounds, which are not produced by a musical instrument or voice, at first glance poses no problem. In order to view it as such, we have to imagine that we are hearing tone names of sounds of a door creaking, of pets, of the engines of motor vehicles, of their horns, of the "howling" wind, of the melodies of cellphones, of the static in the receiver, of bells ringing, of domestic electric appliances, basically of every sound source, whose sounds have a relatively constant number of vibrations, or the character of the sounds heard allows for them to be perceived as a chromatic scale or as a melody. The flood of tone names from all directions - letters or syllables (depending on whether the musician is used to the letter or syllable names of tones), which can form different words or evoke associations of the perceiver in an unexpected or unwanted direction, distract the mind. On the subject of hearing non-music sounds with tone names, I would like to mention an insignificant event, which, nonetheless, made me think about that peculiarity of hearing. I was traveling in a tram, when I caught myself thinking: "The tram is traveling with the speed "Fa" sharp from the first octave. It has to increase its speed to at least "Si" flat, to arrive on time" (when speeding up the sound goes higher). In that moment, I realized that my absolute pitch had begun to affect my conception of speed!

- The tolerance of absolute pitch can be the reason for it to be lost. In continuous training, for example on a piano, which has not been tuned, on which all tones sound at least by a semitone lower than the correct frequencies, the tolerance of absolute pitch prompts the limits, in which for example one sound can be considered to be an "a", to expand up to an interval greater than a semitone. With such a great tolerance absolute pitch becomes unusable. You are still hearing 
tone names, but they are not always the correct ones and each time you hear new music (everything you have listened to and memorized before the incorrect expansion of the tolerance limits, is kept in the memory unchanged) the uncertainty remains of whether the tone names, you have just heard, are accurate.

As can be lost, absolute pitch can also be regained. A well-respected Bulgarian musicologist and Professor shared with me that when he stopped playing actively on the piano, he lost his absolute pitch. He regained it, when he renewed his daily activities with the piano.

\section{Conclusions}

1. Absolute pitch is an inherent musical talent.

2. The talent absolute pitch can be further developed with appropriately focused education.

3. For absolute pitch to be usable in the practice of the professional musician, it is needed for this quality of hearing to be combined with a good state of the other musical abilities, as well as with an appropriate level of linguistic intelligence. This means that the ones who possess absolute pitch have to focus their efforts to developing in a balanced way their musical and general intellectual abilities.

4. When continuously working almost exclusively on a musical instrument that is intonating inaccurately, or when ceasing to be engaged in professional musical activities, the absolute pitch can be lost, but it can also be regained anew.

5. The facts that absolute pitch can be lost, and later on reacquired, as well as that "tolerance" is developed gradually, in the course of activities in music, support the view that this particular characteristic of hearing is psychical and not anatomic.

6. To avoid losing this rarely found musical gift, the ones who have it need to engage in frequent professional activities in music.
The facts that have been presented and the conclusions from them relate to the psychological and practical manifestations of absolute pitch in music. They can be used for the purpose of establishing a pedagogical system for the advancement of this talent.

\section{References}

[1] Gardner, Howard. Intelligence reframed. Sofia, 2004 (Гарднър, Хауърд. Нова теория за множествените интелигентности на 21. век. София, 2004)

[2] Heinrichs I. Musical Hearing and Its Development. Moscow, 1978 (Генрихс И. Музыкальный слух и его развитие. Москва, 1978)

[3] Michel, Paul. Musical Abilities and Performance Skills. Contribution to Musical Psychology. Sofia, 1980 (Михел, Паул. Музикални способности и изпълнителски сръчности. Принос към музикалната психология. С. 1980)

[4] Mincheva, P. Music and Intellect. Sofia, 1994 (Минчева, П. Музиката и интелектьт. София, 1994)

[5] Mincheva, Penka. Musical Education in the General Education School. Sofia, 1994 (Минчева, Пенка. Музикалното възпитание в общообразователното училище. София, 1994)

[6] Nazaykinsky, E. Logic of Musical Composition. Moscow, 1982 (Назайкински, Е. Логика музыкальной композиции. Москва, 1982)

[7] Piaget, Jean. The Psychology of Intelligence. Moscow, 1992 (Пиаже, Жан. Психология интелекта. Москва, 1992)

[8] Tarasova, K. Ontogenesis of Musical Abilities. Moscow, 1988 (Тарасова, К. Онтогенез музыкальных способностей. Москва, 1988)

[9] Wilks, F. Intelligent Emotion. Sofia, 2003 (Уилкс, Ф. Интелигентните емоции. София, 2003) 